\title{
A EXPRESSIVIDADE DOS FONEMAS DA LÍNGUA PORTUGUESA
}

\section{THE EXPRESSIVENESS OF THE PORTUGUESE LANGUAGES PHONEMES}

\section{Donizeth Aparecido dos Santos"}

RESUMO: Este artigo apresenta, primeiramente, um estudo introdutório da Estilística Fônica, no qual é abordada a sua definição, os elementos que ela comporta e um pequeno histórico, destacando o trabalho pioneiro de Charles Bally no reconhecimento da potencialidade expressiva dos fonemas; seguido de um estudo sobre a potencialidade expressiva dos fonemas da língua portuguesa, observando as possíveis sugestões sonoras que vogais e consoantes possuem nesse idioma, baseando-se nos trabalhos de abordagem estilística de José Lemos Monteiro, Mattoso Câmara Jr., Nilce Sant’Anna Martins e Silveira Bueno. A parte final apresenta uma análise estilística da letra da música "Meu bem-querer", do cantor e compositor Djavan, onde são analisadas as sugestões fônicas presentes em alguns dos principais vocábulos do texto, procurando associá-las ao significado semântico dos mesmos e também à mensagem que a canção transmite.

Palavras-chave: Estilística; Sugestões fônicas; Fonemas da língua portuguesa

AвSTRACT: This article presents, first of all, an introductory study on phonic stylism, adressing its definition, the elements involved and a brief history detailing the pioneering work of Charles Bally in recognizing the expressive potential of phonemes. This is followed by a study on the expressive potential of phonemes in Portuguese, observing the possible acoustic suggestions which vowels and consonants possess in this language, based on the works of José Lemos Monteiro, Mattoso Câmara Jr., Nilce Sant'Anna Martins and Silveira Bueno regarding stylistic approach. The final part consists of a statistical analysis of the lyrics to the song "Meu bem-querer", by singer and composer Djavan, wherein phonic suggestions present in some of the main terms used are analyzed, seeking to associate them with their respective semantic meanings and to the greater message conveyed in the song as a whole.

Kerwords: Stylism; Phonic suggestions, Portuguese language phonemes

\footnotetext{
"Doutor em Letras (Estudos Comparados de Literaturas de Língua Portuguesa) pela Universidade de São Paulo (USP) e professor de Língua Portuguesa da Faculdade de Telêmaco Borba (FATEB). Email: donizeth.santos@hotmail.com.
} 


\section{A Estilística Fônica}

A Estilística Fônica, ou Fonoestilística como é chamada por alguns, é um segmento da Estilística que, conforme a definição de Nilce Sant'Anna Martins (1997, p. 149), "trata dos valores expressivos de natureza sonora observáveis nas palavras e nos enunciados". Segundo a autora, fonemas e prosodemas (acento, entoação, altura e ritmo) constituem um complexo sonoro de extraordinária importância na função emotiva e poética. Dessa forma, ela abarca quaisquer que sejam os elementos sonoros de uma palavra, desde a expressividade de uma vogal, passando pelo som macio sugerido por uma consoante, até a entoação do falante, que possam sugerir e exprimir estados emotivos e poéticos.

Maria Luiza Ramos (1972, p. 45) comenta a utilização do aspecto sonoro da linguagem com esses fins, afirmando que "é sabido que muitos autores, desde René Ghil, Mallarmé e Rimbaud, se têm preocupado em estabelecer a relação som-sentido na poesia de diferentes idiomas."

Charles Bally, discípulo de Ferdinand de Saussure, foi um dos primeiros a reconhecer a potencialidade expressiva da matéria fônica, antevendo todas as possibilidades possíveis de extração de significado através da sonoridade das palavras ou enunciados, não poupando, inclusive, o próprio silêncio. Nesse sentido, ele argumenta:

Não há dúvida de que na matéria fônica se escondem posibilidades expressivas. E há que entender por tal modo o que produza sensações musculares e acústicas: sons articulados e suas combinações, jogos de timbres vocálicos, melodía, intensidade, duração dos sons, repetições, assonâncias e aliterações, silêncios, etc. (...)

Assim, junto à fonología propriamente dita há lugar para uma fonología expressiva, que pode trazer muita luz à primeira, analisando o que já o instinto nos diz muito bem: que há uma correspondencia entre os sentimentos e os efeitos sensoriais produzidos pela linguagem. (BALLY, 1969, p. 96) ${ }^{1}$

No Brasil, Silveira Bueno, Mattoso Câmara Jr., José Lemos Monteiro e Nilce Sant'Anna Martins foram os principais linguístas que se ocuparam do estudo da expressividade sonora da Língua Portuguesa. Para o professor Silveira Bueno:

$\mathrm{O}$ aspecto sonoro de uma língua, seja qual for, é o que mais vivamente nos impressiona. Ainda quando não conhecemos tal ou tal idioma, ao ouvi-lo falar, imediatamente, fazemos o nosso juízo estético, segundo nos soam as palavras, segundo seu aspecto sonoro. O estilista, embora escrevendo, está sob o domínio da construção fonética dos termos que emprega porque, ainda quando silenciosamente compõe a sua página, o seu livro, o seu artigo de jornal, está ouvindo mentalmente os vocábulos que a pena vai debuxando no papel. (BUENO, 1964, p. 62)

Para o linguista Mattoso Câmara Jr. (1977), cabe à Estilística Fônica da língua portuguesa apreciar o caráter espontâneo e expressivo das suas vogais e consoantes, aproveitando-se as contribuições de outras

${ }^{1}$ Tradução do autor. 
línguas a respeito dos sons da fala similares aos do português. Nesse sentido, José Lemos Monteiro (1991) observa que os sons vocálicos da língua portuguesa intensificam as sugestões visuais (forma, cor etc.) e os traços afetivos que delas decorrem, enquanto que sons consonantais se relacionam às espécies auditivas, cinéticas, táteis etc... Dessa forma, conforme afirma Nilce Sant'Anna Martins (1997,26), "os sons da língua podem provocar-nos uma sensação de agrado ou desagrado e ainda sugerir ideias, impressões."

Com base nos estudos desses quatro linguistas brasileiros (Silveira Bueno, Câmara Jr, Monteiro e Martins), abordaremos a expressividade dos fonemas vocálicos e consonantais da língua portuguesa, observando as principais sugestões que eles oferecem e não se esquecendo da ressalva feita por Martins (1997, p. 38) de que a matéria fônica de uma língua "é extremamente subjetiva, imprecisa, dificilmente classificável com certa exatidão, sendo preciso evitar excessos imaginativos sem apoio nas qualidades físicas dos sons."

A EXPRESSIVIDADE DOS FONEMAS DA LÍNGUA PORTUGUESA

\section{VOGAL ORAL / A /}

A vogal / a /, segundo Nilce Sant'Anna Martins (1997, p. 29) é “o fonema mais sonoro, mais livre, de todo o nosso sistema fonológico" e "traduz sons fortes, nítidos e reforça a impressão auditiva das consoantes que acompanha”. Conforme a autora, esse valor pode ser sentido em interjeições, onomatopeias e palavras que sugerem: risadas (quá-quá-quá, ah, ah, ah, gargalhada), vozes altas (algazarra), tagarelice (blá-blá-blá, maitaca), batidas audíveis (pá, pá, pá, plaft, craque), ideias de claridade e brancura (alvorada, prata, claro, madrugada, luar), amplitude (mar, vasto, colossal, imensidade ) e sentimentos positivos (felicidade, formidável, paz, calma e tranquilidade).

\section{VOGAL ORAIS / E / E / É /}

A vogal / e / (fechada) é neutra, discreta e oferece pouca expressividade significativa. No entanto, Silveira Bueno (1964, p. 76), por considerá-la cinzenta, surda e indecisa, observa que ela "fica bem nas descrições dos crepúsculos, dos estados interiores de almas crepusculares, dos momentos cinzentos da vida humana".

Já vogal / é / (aberta) possui mais expressividade. Para Nilce Sant'Anna Martins (1997), ela produz um excelente efeito na indicação da estrudência, conforme em “... pajés em poracés batendo os pés”, verso de um poema de Cassiano Ricardo.

\section{VOGAL ORAL / I /}

A vogal / i / é uma das vogais mais exploradas estilisticamente. Ela exprime e sugere sons agudos e estridentes como: grito, apito, pio, tinir, assobio, tinido, estrídulo, grilo, buzina, sino, bem-te-vi e violino. Para Silveira Bueno (1964), o i é frio, penetrante, agudo como espinho. Nesse sentido, Nilce Sant'Anna Martins explica a relação existente entre a articulação da vogal com suas sugestões sonoras e semânticas: 
- O estreitamento do conduto bucal na produção do / i / se coaduna com a expressão de pequenez, estreiteza, agudez: mínimo, mini, estrito, fio, fino, espinho, formiga. Alguns dos valores expressos pelo diminutivo (em -inho, -im, -ito, -ilho ) se relacionam com a vogal tônica do sufixo. A agudez pode ser de ordem moral, intelectual: ironia, agonia, perfídia, malícia, sutil, mesquinho, cainho". (MARTINS, 1997, p. 33)

\section{VogAIS ORAIS / O / E / Ó /}

Como as ideias que sugerem são as mesmas, abordamos as vogais / o / (fechada) e / ó / (aberta) conjuntamente. Elas são classificadas como vogais posteriores, médias e arredondadas, podendo sugerir ruídos surdos (estrondo, estouro, bomba, rouco) e formas arredondadas (globo, sol, ovo, redondo, roda, gordo, balofo, olho, bola). Segundo o professor Silveira Bueno (1964, p. 77), “a vogal o indica opulência, grandeza, majestade, mas também calor, mormaço. Basta ler, em voz alta, as palavras: ouro, calor, morno, trono, bomba, estrondo, balofo, fofo, redondo, etc."

\section{VOGAL ORAL / U /}

A vogal / u / sugere ideias de fechamento e escuridão (tubo, gruta, furna, cafua), tristeza e morte (túmulo, urubu, fúnebre, luto, viúvo, sepultura, jururu, sepulcro), e ruídos surdos (marulho, bufo, murmúrio, barulho, queixume, sussurro, gluglu, urro e zurro).

Por ser um dos fonemas mais expressivos da língua portuguesa, José Lemos Monteiro fez a seguinte classificação, baseando-se em um inventário elaborado por Alfredo Bosi sobre os traços semânticos de palavras que contêm a vogal / u /:

I) Obscuridade (material ou espiritual) - escuro, fundo, turvo, gruta, negrume, cafuso, crepúsculo, furna, fusco, túnel, penumbra, noturno, bruma etc.

II) Fechamento - apertura, caramujo, casulo, cumbuca, conduto, cuca, ocluso, oculto, recluso, tubo, urna, útero, vulva etc.

III) Tristeza e desgraça - agrura, amargura, angústia, azedume, carrancudo, casmurro, infortúnio, lamúria, queixume, soturno, taciturno, urubu etc.

IV) Sujeira, podridão, morbidez - chulo, corrupto, culpa, estupro, imundo, monturo, pus, pústula, putrido etc. $\mathrm{O}$ Diabo é Belzebu, Cafuçu, Cujo, Exu.

V) Pesar total, morte - ataúde, catacumba, defunto, fúnebre, luto, lúgubre, moribundo, múmia, sepulcro, túmulo, tumba, sepultura etc." (MONTEIRO, 1991, p. 132)

\section{VOGAIS NASAIS}

De acordo com Nilce Sant' Anna Martins (1997, p. 32-3), a ressonância nasal torna as vogais aptas a exprimir sons velados e prolongados (zumzum, zumbido, ron-ron, gongo, trim-trim, tanger, planger) e sugerir distância, lentidão, moleza, melancolia (longe, longínquo, distante, bambo, brando, manso, langue, pranto, lamento). 


\section{FONEMAS CONSONANTAIS}

Segundo José Lemos Monteiro, as consoantes se relacionam às espécies auditivas, cinéticas e tácteis. Nesse sentido, ele esquematizou seus principais valores da seguinte forma:

\section{SENSAÇÕES AUDITIVAS}

/ p / /b / - explosões, ruídos abafados

/ t / / d / - ruídos secos e violentos, percussões

/ k/ / g / rachaduras, ruídos demorados

Ex: bomba, pancada, tombar, retumbar, estampido, estrépido, estrondo, grito, brado, estalo, tambor, palpitar, borbulhar, pipocar, catarata, matraca, etc.

\section{/ f / / V / - sopros}

/ $\mathrm{x} /$ / j / - cochichos, chios, gemidos

/ s / / z / - assobios, sibilos prolongados

Ex: vento, vendaval, furacão, tufão, voz, chiado, chuva, silvo, ciciar, zumbir, sussurro, etc.

/ r / / R / - vibrações, rasgos, percussões demoradas

/ $\mathrm{m} / / \mathrm{n} /$ / N / - roncos fracos, zumbos, mugidos, prolongamentos de zumbidos

Ex: rugir, urrar, pororoca, rosnar, estraçalhar, fremir, bramir, murmúrio, bronze, burburinho, murmurejar, etc.

SENSAÇÕES CINÉTICAS

/ 1 / / L / - fluência, deslizamento

/ r / / R / - rapidez, tremor

/ f / / / - escapamento, fuga
Ex: luz, brilho, livre, flutuar, rolar, correr, tremor, tremeluzir, tremelique, frio, calafrio, relâmpago, voar, fugir, veloz, etc.

SENSAÇÕES TÁCTEIS

/ l / / L / - leveza

/ p / / b / - pesadume

/ t / / R / - aspereza

/ s / / z / / m / - suavidade

Ex: leve, fluído, mole, floco, áspero, duro, macio, suave, rapar, ríspido, paquiderme, etc. (MONTEIRO, 1997, p. 102)

O esquema elaborado por Monteiro resume muito bem a expressividade dos fonemas consonantais da língua portuguesa. No entanto, como nem todos os fonemas consonantais possuem expressividade, e muitos deles sugerem as mesmas ideias, definiremos seus respectivos valores expressivos pelos grupos oclusivos, constritivos e nasais, que abarcam todas as consoantes expressivas da língua portuguesa.

\section{CONSOANTES OCLUSIVAS}

O grupo oclusivo comporta as consoantes: / p / (bilabial surda), / b / (bilabial sonora), / t / (linguodental surda), / d / (linguodental sonora), / k / ( velar surda) e / g / (velar sonora). Sobre esse grupo de fonemas consonantais, Nilce Sant'Anna Martins observa que:

As consoantes oclusivas, pelo seu traço explosivo, momentâneo, prestam-se a reproduzir ruídos duros, secos, de batidas, pancadas, passos pesados, (...). Saliente-se que as surdas ( / p /, / t/, 
/ k / ) dão uma impressão mais forte, violenta, do que as sonoras ( / b /, / d /, / g / ). Várias palavras iniciadas por consoante oclusiva bilabial são empregadas como interjeições, exprimindo uma explosão de surpresa, espanto, raiva, indignação: Papagaio! Ora bolas! Pipocas! Porra! Pô! Puxa! Em vocábulos depreciativos a oclusiva pode ter uma explosão mais acentuada por conta do estado emocional do falante: burro, besta, bandido, pateta, paspalho, bruto, estúpido, tonto (bb, pp, tt).

\section{$(\ldots)$}

Além de sugerir ruídos ou objetos que os produzem (estalo, estrépido, estampido, trote, pancada, grito: chicote, taca, porrete, estadulho, trabuco); as oclusivas surdas, conforme Morier, convêm à evocação de seres, coisas, atos, qualidades e sentimentos ligados às ideias de força e intensidade: déspota, tirano, ditador, Titã, potestade, prepotência, prepotente, possante, bruto, implacável, tempestade, trovão, furação, tapa, bofetão, etc. ( MARTINS, 1997, p. 34 )

A combinação da bilabial sonora / b / e da linguodental surda / $t$ /, com a vibrante simples / r /, exprime rupturas, quebras e fragmentações (trovão, trincar, quebrar, brotar); e afeição e ternura são sugeridas em palavras iniciadas pela bilabial sonora / b / (beijo, bem, bondade).

\section{CONSOANTES CONSTRITIVAS}

Faz parte desse grupo as consoantes: / f / (fricativa labiodental surda), / v / (fricativa labiodental sonora), / s / (fricativa alveolar surda), / z / (fricativa alveolar sonora), / x / (fricativa palatal surda), / j / (fricativa palatal sonora), as laterais / / (alveolar sonora) e / lh/ (palatal sonora), e as vibrantes / r / (alveolar sonora) e / R / (velar sonora).

Em relação à expressividade dessas consoantes, Nilce Sant'Anna Martins faz as seguintes afirmações:

- As consoantes constritivas, pelo seu caráter contínuo, sugerem sons de certa duração, bem como as coisas e fenômenos que os produzem.

- As labiodentais / f / e / v / imitam sopros, podendo ter valor expressivo em vocábulos com voz, vento, fala, fofoca, flaflo...

- Os sons sibilantes podem ser imitados também pelas labiodentais (fium!), mas o são sobretudo pelas alveolares / s / e / z /: sibilo, assovio, silvo, cicio, soluço, suspiro, zunir, zumbir...

- As fricativas palatais recebem também a denominação de chiantes pela sugestão de chiado: chua, xixi, cochicho, esguicho, repuxo, lixa, chusma, enxame. (MARTINS, 1997, p. 35)

Quanto às consoantes laterais / $1 /$ e / lh /, elas podem sugerir ideias de fluência e deslizamento por causa do ar que escoa pelos lados da boca no momento da fonação. A fluência da luz é a mais comum (brilho, claro, lua).

Sobre as constritivas vibrantes / $\mathrm{r} / \mathrm{e}$ / R /, elas podem exprimir sentimentos de cólera, medo e violência (ira, furor, horror, raiva, tiro, guerra, terror), e segundo Nilce Sant'Anna Martins (1997, p.37), “- A vibrante 
dupla / R /, sozinha ou em grupo com oclusivas, se ajusta à noção de vibração, atrito, rompimento, abalo, como se pode sentir nos vocábulos rachar, ranger, rasgar, romper, roer, ruir, arranhar, arrancar, estropiar, estraçalhar, troar, etc."

\section{CONSOANTES NASAIS}

As consoantes nasais portuguesas / $\mathrm{m} /$ (bilabial sonora), / n / (linguodental sonora) e / h / (palatal sonora) são consideradas "moles, doces, e se harmonizam com as palavras e enunciados em que prevalece a ideia de suavidade, doçura, delicadeza" (MARTINS, 1997, p. 37), como em: ameno, manso, mole, mimoso, amor, meigo, murmúrio, mel, menino, ninar, harmonia, melodia, musgo, ninho, sonho, etc. Muito expressiva é a consoante bilabial nasal / $\mathrm{m} /$, que pode sugerir sentimentos de afeição e ternura em palavras como mãe, mimar, amor e meigo.

As SUGESTÕES FÔNICAS PRESENTES NA LETRA DA MÚsica “Meu bem-Querer”, De DJaVAN

As letras de músicas são textos poéticos e emotivos se analisadas sob a luz das funções da linguagem concebidas por Roman Jakobson (1969), e dessa forma são constituídas por recursos estilísticos que visam despertar fantasias e emoções no ouvinte. Dentre esses recursos estilísticos está a sugestão fônica, que na grande maioria das vezes não é percebida pelo ouvinte devido às peculiaridades da música e a supremacia que as figuras de linguagem possuem no texto musical. Também é importante observar que esse recurso estilístico utilizado em larga escala por poetas como Olavo Bilac, Guilherme de Almeida, Manuel Bandeira, Cecília Meireles e Eugênio de Castro, entre outros, muitas vezes é utilizado inconscientemente na poesia e na composição da letra de música. Por isso, nem sempre a expressividade sonora de um vocábulo é usada de forma intencional pelo autor.

Nesse sentido, considerando-se que os sons vocálicos e consonantais podem sugerir ideias e impressões, expressar sentimentos e provocar sensações de agrado ou desagrado (MARTINS, 1997), apresentamos uma análise das sugestões fônicas identificadas na letra da música "Meu bem-querer", do cantor/ compositor Djavan, tendo por base os elementos teóricos da Estilística Fônica apresentados na primeira parte desse trabalho.

Meu bem-querer

É segredo, é sagrado

Está sacramentado

Em meu coração

Meu bem-querer

Tem um quê de pecado

Acariciado pela emoção

Meu bem-querer, meu encanto

Tô sofrendo tanto

Amor

E o que é o sofrer

Para mim que estou

Jurado pra morrer de amor? (DJAVAN, 1980)

Em "Meu bem-querer", talvez a música mais conhecida de Djavan, logo no primeiro 
verso da estrofe inicial, "Meu bem-querer", há a combinação da consoante bilabial nasal / m / e da vogal / e / no pronome possessivo "meu", e destas com a consoante bilabial oclusiva / b / no primeiro termo do substantivo composto "bem-querer". A vogal / e /, segundo Nilce Sant'Anna Martins (1997), é neutra, discreta e não oferece nenhuma expressividade marcante, mas as bilabiais / $\mathrm{m} / \mathrm{e} / \mathrm{b} /$, de acordo com a autora, podem sugerir sentimentos de afeição e ternura. Considerandose que "bem-querer" significa amor ou pessoa amada, alguém que se ama muito, a sugestão fônica das duas consoantes ajusta-se ao significado semântico, expressando afeição e ternura por esse "bem-querer" afirmado possessivamente devido à presença do pronome "meu".

No segundo, terceiro e quarto versos, "É segredo, é sagrado/ Está sacramentado/ Em meu coração", ocorre a aliteração ${ }^{2}$ da consoante constritiva sibilante / $\mathrm{s} /$ que integra as sílabas iniciais dos vocábulos "segredo, sagrado, sacramentado, está", e a sílaba final de "coração". De acordo com José Lemos Monteiro (1991), a sibilante / s /, evoca a interjeição psiu, um pedido de silêncio, e "participa dos exemplos de imitação sonora quando se fala dos assobios, dos sussurros, do ciciar dos pássaros". Levando-se em consideração o significado de "segredo" (sigilo, confidência, discrição, mistério, algo que não se deve revelar), "sagrado" (algo divino, venerável, que não dever ser violado) e "sacramentado" (quando é dado caráter sagrado a alguma

${ }^{2}$ Repetição de uma mesma consoante nas sílabas iniciais, tônicas, e também átonas das palavras que formam um verso, uma frase ou oração. coisa), constata-se que essa sequência da sibilante provoca uma "harmonia imitativa", sugerindo a ideia de um sussurro, de alguém que tem medo que suas palavras possam ser ouvidas, pois o que está por trás delas é algo extremamente sigiloso para ele: o "bem-querer" está "sacramentado" porque lhe foi dado caráter "sagrado", e sendo "sagrado" é algo que não deve ser violado, e assim, é um "segredo" que não se pode revelar. O "segredo" é a identidade do "bem-querer", o que nos explica a sugestão de sussurro e silêncio em torno do enunciado.

Mas, ao mesmo tempo em que os vocábulos segredo, sagrado e sacramentado expressam esse pedido de silêncio em razão da presença da sibilante / s / nas sílabas iniciais, eles possuem também em suas estruturas morfológicas as consoantes oclusivas / g / e / k / associadas à vibrante simples / r / nas sílabas intermediárias, e as oclusivas / $\mathrm{t}$ / e / d / nas sílabas finais, o que teoricamente destrói a sugestão de silêncio das iniciais, pois, segundo José Lemos Monteiro (1991), as oclusivas / k / e / g / sugerem rachaduras e ruídos demorados, enquanto que / $\mathrm{t} / \mathrm{e} /$ $\mathrm{d}$ /sugerem ruídos secos e violentos, e / r /, vibrações, rasgos e percussões demoradas. Relembremos também a observação feita por Nilce Sant'Anna Martins sobre essas consoantes oclusivas.

... pelo seu traço explosivo, momentâneo, prestam-se a reproduzir ruídos duros, secos, de batidas, pancadas, passos pesados, ( ... ) Saliente-se que as $\operatorname{surdas}(/ \mathrm{p} /, / \mathrm{t} /, / \mathrm{k} /)$ dão uma

${ }^{3} \mathrm{~A}$ "harmonia imitativa" consiste numa aproximação dos sons físicos através de sons linguísticos. 
impressão mais forte, violenta do que as sonoras (/b/, / d /, / g /, ao passo que a vibrante / $\mathrm{r}$ / sozinha ou em grupo com oclusivas, se ajusta à noção de vibração, atrito, rompimento, abalo. (MARTINS, 1997, p. 34)

Como essas combinações consonantais vêm após a sibilante / s /, elas quebram a sugestão de silêncio e sugerem, no contexto da letra da música, ruídos que escapam ao controle do sujeito poético. É como se ele caminhasse na ponta dos pés tentando não fazer barulho e não conseguisse evitar que soasse o som dos seus passos. Uma vez que a canção fala de um amor secreto e proibido, essa sugestão exprime a dificuldade e os obstáculos que o sujeito poético enfrenta para manter em sigilo esse sentimento e a impossibilidade de se calar algo sobre o qual já não se tem mais controle.

$\mathrm{Na}$ segunda estrofe, o vocábulo "pecado", que realmente o "bem-querer" tem, pois o "quê" é a primeira sílaba de "querer", é formado pelas consoantes oclusivas / p /, / k/ e / d /, que, conforme afirmamos anteriormente, sugerem explosões, rachaduras, pancadas e ruídos secos e violentos. Analisando-se o significado semântico do termo, constatamos que "pecado" é uma transgressão, uma quebra, o rompimento de um preceito religioso (e se é religioso é sagrado), e ajustando-se esse significado à sugestão fônica das consoantes, verifica-se que há um equilíbrio entre ambos, pois o ato de romper, quebrar alguma coisa está ligado ao som que essa ação provoca (explosões, ruídos secos, geralmente violentos), e sendo assim a rachadura (a ruptura) que o "pecado" provoca casa-se perfeitamente com o aspecto fônico das consoantes. Vejamos: o / p / da sílaba inicial sugere uma explosão, o / k / da intermediária sugere a ruptura provocada pelo som explosivo anterior e o / d / átono, abranda a violência das consoantes anteriores, como se diminuísse de intensidade após o abalo provocado. Também é interessante salientar que "pecado" remete seu sentido aos vocábulos da primeira estrofe "segredo, sagrado, sacramentado", revelando-nos o porquê do "bem-querer" ser segredo, sagrado e sacramentado.

No verso seguinte, "Acariciado pela emoção", a sonoridade dura e seca do verso anterior, provocado pela predominância das consoantes oclusivas, é substituída pela suavidade e maciez que o fonema constritivo sibilante / s / e o nasal / m / dão ao verso, quando combinados com a vibrante simples / r / e a vogal / a /. De acordo com Nilce Sant'Anna Martins (1997), a consoante nasal / m /, considerada mole e doce, se harmoniza com as palavras e enunciados em que prevalece a ideia de suavidade, doçura e delicadeza. Desse modo, essa associação de fonemas expressa também, além das já citadas, ideias de paz, afeição, ternura e felicidade.

No quarto e quinto versos, "Meu bem-querer, meu encanto/Tô sofrendo tanto", há a predominância dos fonemas vocálicos nasais / ã / e / ê /. A ressonância nasal, segundo Nilce Sant'Anna Martins (1997), torna as vogais aptas a sugerir distância, lentidão, moleza e melancolia. Assim a nasalização dá um tom melancólico ao substantivo "encanto", ao verbo "sofrendo" e ao advérbio de intensidade "tanto". O caráter secreto e 
proibido dos primeiros versos da letra da música e esses últimos versos melancólicos dão a impressão que a suavidade, a doçura e a paz do terceiro verso foram apenas um lampejo de felicidade.

A terceira e última estrofe da letra da música, composta por quatro versos que formam um período interrogativo, contém dois vocábulos foneticamente muito expressivos: os verbos "sofrer" $e$ "morrer". O primeiro possui em sua estrutura morfológica a ocorrência por duas vezes da vibrante simples / $\mathrm{r} /$ que sugere tremor e medo; e o segundo, além da vibrante simples em seu final, tem em seu centro a vibrante dupla / $/$ que pode sugerir medo, vibração, rompimento e abalo. A sugestão fônica dessas duas consoantes reforça o significado que os dois verbos possuem: o tremor e o medo fazem parte da dor e do sofrimento, e o medo, a vibração e o abalo se ajustam à ideia de morte.

Essa análise foi pautada somente nas possíveis sugestões sonoras que os fonemas em língua portuguesa oferecem, sem nos determos nas figuras de linguagem (semânticas e sintáticas) que o texto possui. Com isso, pretendemos mostrar que a sugestão sonora dos fonemas que constituem alguns dos principais vocábulos de "Meu bem-querer" confirma o significado semântico da letra da música.

\section{À GUISA DE CONCLUSÃO}

Como acabamos de ver, os fonemas da língua portuguesa oferecem inúmeras possibilidades expressivas, sugerindo os mais variados sentimentos, impressões, sons, expressões, formas e estados psicológicos.
E todo esse potencial sonoro é aproveitado por poetas, cantores, compositores musicais e atores que dominam esse recurso estilístico que o idioma oferece para o enriquecimento expressivo de seus trabalhos. E a partir daí, entendemos a grande importância que a expressividade fônica possui e, mais ainda, o quanto é importante adquirir este conhecimento que é uma das chaves para a compreensão e interpretação de textos literários (principalmente a poesia) e letras de músicas em língua portuguesa.

Também se faz necessário aqui, relembrar a grande evidência que a relação som-sentido tem na maior parte das sugestões dos vocábulos em português, como a sugestão fina e aguda da vogal / i /, de redondez da vogal / o /, os ruídos duros e explosivos das consoantes oclusivas, o chiado das fricativas, e o sopro das consoantes / f / e / v /, entre muitos outros exemplos.

\section{REFERÊNCIAS BIBLIOGRÁFICAS}

BALLY, Charles. El lenguaje y la vida. Trad. Amado Alonso. 5 ed. Buenos Aires: Editorial Losada, S.A., 1967.

BUENO, Silveira. Estilística brasileira. São Paulo: Saraiva, 1964.

DJAVAN. Meu bem-querer. Rio de Janeiro: Tapajós, 1980. disponível em www.djavan.com. br. Acesso em: 20 out. 2001.

JAKOBSON, R. Lingüística e poética. In.: Lingüística e comunicação. Trad. Isidoro Blinkstein e José Paulo Paes. São Paulo: Cultrix, 1969.

MARTINS, Nilce Sant'Anna. Introdução a estilística: expressividade na língua 
portuguesa. 2 ed. ver. e aum. São Paulo: T.A.

Queiroz, 1997.

MATTOSO CÂMARA JR, Joaquim. Contribuição

à estilística portuguesa. 3 ed. ver. Rio de Janeiro: Ao Livro Técnico S/A, 1977.

MONTEIRO, José Lemos. A estilística. São

Paulo: Ática, 1991.

RAMOS, Maria Luiza. Fenomenologia da obra

literária. 2 ed. São Paulo: Forense, 1972.

Recebido para publicação em 16 jan. 2016.

Aceito para publicação em 08 set. 2016. 